\title{
Today's improvement in asthma treatment: role of MART and Easyhaler
}

\author{
Fabiano Di Marco \\ Department of Health Sciences, University of Milan; Head Respiratory Unit, Papa Giovanni XXIII Hospital, Bergamo, Italy
}

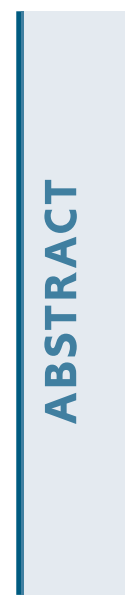

\begin{abstract}
Asthma affects more than 330 million people worldwide, but many analyses have shown that there are still a lot of unmet needs for both patients and physicians in the treatment of asthma: poor adherence to treatment is one of the main causes of sub-optimal clinical results. Maintenance and Reliever Therapy (MART) with the combination of formoterol and inhaled corticosteroids (ICS) has an established scientific rationale and demonstrated to reduce asthma exacerbations. The aim of this review is to highlight how in asthmatic patients MART can be able to express its maximum therapeutic potential when administered through an 'ideal inhaler'. Since the treatment may be necessary several times a day, the use of a single combination inhaler simplifies the management, potentially improving adherence; moreover, easiness of use and comfort in administration of asthma treatment devices are not secondary aspects. Asthmatic patients are often young, with a normal relational and working life and they could request for a comfortable and not too noticeable device. Finally to the "ideal inhaler" is requested to guarantee accuracy, dose consistency, and resistance to stress conditions. Easyhaler ${ }^{\circledR}$ more closely demonstrates many expected characteristics: effective, consistent performance regardless of inspiration rate, stability, versatility, with several patient acceptability advantages. Asthma control is enhanced by a strong adherence obtained through the combination in a single inhaler of both maintenance and reliever therapy and the availability of a device as close as possible to the characteristics of the ideal inhaler.
\end{abstract}

Key words: Asthma; treatment adherence and compliance; anti-asthmatic agents; budesonide formoterol fumarate drug combination; inhalation device.

Correspondence: Fabiano Di Marco, Head Respiratory Unit, Papa Giovanni XXIII Hospital Bergamo, Piazza Oms 1, 24127 Bergamo, Italy. E-mail: fabiano.dimarco@unimi.it

Conflict of interest: FDM reports personal fees from Menarini, during the conduct of the study; grants and personal fees from Boehringer Ingelheim, GSK, Chiesi, and Novartis, personal fees from Zambon, Guidotti/Malesci, Menarini, Mundipharma, and TEVA, outside the submitted work.

Funding: This publication was unconditionally funded by Menarini International Operations Luxemburg S.A. (M.I.O.L.). 


\section{Introduction}

Asthma is one of the most common chronic diseases in the world, affecting more than 330 million people worldwide, with a prevalence that is still growing in most countries (approximately around $1-18 \%$ of population worldwide) $[1,2]$.

Asthma is a global health problem that causes a considerable negative impact on patients' quality of life and a substantial burden on healthcare systems and on society through a loss of productivity in the workplace $[3,4]$. In particular, exacerbations are associated with absences from work or school and increased healthcare costs [5-7]. As with other chronic diseases, poor adherence to maintenance medication is a big issue in asthma [8].

The most commonly observed pattern is the use of medication only when symptoms occur, and suspension of treatment when it is perceived as unnecessary [9]. The adherence to inhaled corticosteroids is very poor both in adults and children and has been estimated an average cover of dispensation less than $25 \%$ of days [10].

The aim of this review is to discuss the role of the Maintenance and Reliever Therapy (MART) with the combination of formoterol and inhaled corticosteroids (ICS) and the characteristics of an "ideal inhaler" on the management of asthma according with the more recent evidence and guidelines.

\section{Asthma management and GINA document}

Two recent papers underlined the controversies in terms of management and treatment recommendations and the discordance between "real life" and the scenario described in the recommendations. Consequently, it is clear that how there are still a lot of unmet needs for both patients and physicians in the treatment of asthma $[11,12]$.

GINA guidelines suggested, for patients with symptoms less than twice a month and no exacerbation risk factors (step 1), as needing low dose ICS-formoterol as first-line therapy and low dose ICS taken whenever short-acting beta-agonist (SABA) is taken or daily low dose ICS as an alternative approach.

For patients with mild persistent asthma (step 2), daily low dose ICS plus as-needed SABA, or as-needed low dose ICS-formoterol are recommended as the first choice. Leukotriene receptor antagonist is an alternative treatment for these mild persistent asthma patients but this intervention is generally less effective than regular ICS especially in preventing exacerbations. Other options are low dose ICS taken whenever SABA is taken, and daily low dose ICS-LABA [13].

The reasons for the suggestions of GINA document are mainly based on the results of data collected on Budosenide/Formoterol (BUD/FORM) [14-17]. The recommendation of ICS at step 1 is an innovative, and partially evidence-based decision for different reasons: ongoing airway inflammation and elevated exhaled nitric oxide levels and bronchial biopsy evidence of airway inflammation have been found also in patients with mild intermittent asthma [18]. Adding ICS as needed in all patients with asthma, even in step 1, helps to reduce symptoms and exercise-induced bronchoconstriction, as well as to reduce risk of serious exacerbations and subsequent decline in lung function [12,19,20].

Although all guidelines and most physicians usually recommend as-needed SABA only as a quick relief of symptoms, some patients with mild asthma are still "addicted" to SABA [18]. This is a problem of great medical relevance as confirmed in the Finnish Asthma Program, where the introduction of anti-inflammatory treatment (principally ICS) was associated with improved control and reduction of the burden and cost of asthma [21].

\section{The maintenance and reliever therapy}

The use of ICS/LABA as needed has been introduced with an approach called MART, which is an acronym that stands for Maintenance and Reliever Therapy.

Maintenance and Reliever Therapy is a combination in a single inhaler to be used as both preventer in the daily maintenance therapy and reliever of symptoms when required, as part of a specific treatment regimen. MART is only available for ICS and LABA combinations in which the LABA has a fast-acting component, e.g. formoterol.

The rationale for the use of MART, even in patients with reliever use of $<1$ occasion/day, is based on rapid onset of action, as rapid symptomatic relief and on its simplicity, that may help to improve adherence which is often poor, because patients cannot increase their exposure to beta-agonist therapy without concomitantly increasing their exposure to ICS. There are also advantages for patients who need only a single inhaler, in achieving the treatment goals described in guidelines. In fact, MART is more effective at reducing exacerbations and improving daily asthma control than the same maintenance dose of BUD/FORM plus as-needed SABA [22]. BUD/FORM used as needed results equally effective as budesonide maintenance therapy in preventing moderate tosevere exacerbations, with a reduction to less than one fifth of the inhaled glucocorticoid exposure [12,14,15].

A very recent review has confirmed that patients with asthma treated with BUD/FORM MART achieved the same or better asthma symptom control compared with ICS/LABA plus SABA regimens at similar or higher ICS dose, across a range of severities of persistent asthma, results in a $40-50 \%$ reduction of exacerbations compared with an ICS-based treatment approach plus as-needed SABA as reliever and considerably lower annual requirement for oral corticosteroids. As-needed, BUD/FORM has also recently been shown to be more effective as a reliever in mild asthma than SABA alone, reducing exacerbations by up to $64 \%$ in the SYGMA studies, two double-blind, randomised, multicentre trials [23].

MART strategy reduces emergency department and hospitalization rates as confirmed in a recent meta-analysis [24].

\section{Inhalation devices}

A prerequisite for any inhaler device used for the treatment of airway diseases is that it should perform consistently, delivering a predictable and reproducible drug dose during repeated use, i.e. from the first to the last labelled dose. The inhaled particles should also have a size making them respirable, i.e. particles of aerodynamic size $<5 \mu \mathrm{m}$, particles smaller than $1 \mu \mathrm{m}$ are exhaled to a large degree depending on the particle size distribution [25].

For some patients, poor coordination with use of a pMDI (pressurized metered dose inhaler) is the main problem that can lead to dosing errors, but also with some Dry Powder Inhalers (DPIs) it is possible to notice inhalation manoeuvre problems. The effectiveness of a powdered drug to inhale depends on the patient and his ability to generate an adequate inspiratory flow rate and on the intrinsic resistance of the DPI generating turbulent airflow effective in de-agglomeration of the drug substance from its carrier molecule. The technical design of the DPI influences this: there are high -, medium-, and low-resistance DPI devices. With low-resistance DPIs, the de-agglomeration of the drug highly depend on the patient's inhalation airflow rate, while the de-agglomeration of the powdered drug are optimized in the case of medium- and highresistance DPIs [26]. Moreover, a systematic review of patients with asthma and COPD found that up to $94 \%$ of DPI users made 
at least one inhaler error when examined by a healthcare professional (HCP) [27].

The introduction of inhalers that address current unmet needs have the potential to improve patient inhalation technique, to increase patient treatment adherence and therefore to improve patient outcomes; at the same time reducing the patient and economic burden associated with asthma [28].

\section{Easyhaler ${ }^{\circledR}$}

The Easyhaler ${ }^{\circledR}$ device-metered dry powder inhaler (dmDPI) (Orion Pharma, Espoo, Finland) has an innovative design to resemble a conventional pMDI in terms of shape and operating principles, being both simple and practical. It consists of seven plastic parts, a metering cylinder spring, and plastic components [29]; it has added design features, such as a protective case and dose counter [30]. Internally, it contains powder (active substance(s) mixed with the carrier lactose). Accurate dosing is achieved by shaking up and down the device and pushing down the overcap of the device that rotates the metering cylinder at the bottom of the bulk chamber (Figure 1) before inhaling the drug. The mouthpiece is designed and shaped to allow optimal drug distribution to the airways. The performance of Easyhaler ${ }^{\circledR}$ is dependent on the inspiratory effort produced by the patient, the built-in resistance of the inhaler, as well as the aerosolization geometry of the device [31].

Efficacy, safety, and acceptability of Easyhaler ${ }^{\circledR}$, were compared to different inhalers: in four of these studies the comparison device was an MDI combined with a spacer, in one study an MDI without a spacer, and in four studies a DPI. Five items from the acceptability questionnaire were selected for the meta-analysis: ease of use, ease of learning how to use, ease of dosing the drug, ease of inhaling, and the patients' choice of device. In a homogeneous population of patients with moderate to severe asthma, specific satisfaction with inhaler (measured with the FSI-10 questionnaire) was statistically significantly higher with Easyhaler ${ }^{\mathrm{TM}}$ $(43.8 \pm 7.1)$ compared with Turbuhaler ${ }^{\mathrm{TM}}$ or Diskus $^{\mathrm{TM}}$ $\left(\right.$ Accuhaler $\left.^{\mathrm{TM}}\right)(41.3 \pm 7.6)(\mathrm{p}<0.01)$. Moreover, a statistically significant higher percentage of patients showed high satisfaction with Easyhaler $^{\mathrm{TM}}\left(62.4 \%\right.$ of patients) than with Turbuhaler ${ }^{\mathrm{TM}}$ or Diskus $^{\mathrm{TM}}$ (Accuhaler $\left.{ }^{\mathrm{TM}}\right)(43 \%$ of patients) $(\mathrm{p}=0.01)$ [32].

Patients often perceive MDIs difficult to use and the MDIs are often found to be used incorrectly despite training [33], while the Easyhaler $^{\circledR}$, even when the patients are naïve, was easier to learn and use than their prior device [34].

Equivalent efficacy has been demonstrated between budesonide inhaled from an Easyhaler ${ }^{\circledR}$ and from a Turbuhaler ${ }^{\circledR}$ in corticosteroid-naive asthmatic adults [35]. The similar delivery of budesonide to the body in healthy male adults between Easyhaler ${ }^{\circledR}$ and Turbuhaler $^{\circledR}$ devices was confirmed in single [36] and multipledose studies [37] involving both adult [35,38] and children [39].

The EMA guideline on the requirements for clinical documentation for orally inhaled products (OIPs) has been followed in the development of BUD/FORM Easyhaler ${ }^{\circledR}$. After pharmacokinetic studies, a multicenter, randomised, single-dose, double-blind, double-dummy, crossover study in comparison to Turbuhaler ${ }^{\circledR}$ showed that the products are equivalent within dose levels, the maximum response and the duration of effect are similar after both products. In addition, the results confirmed equivalent bronchodilator efficacy. Turbuhaler ${ }^{\circledR}$ and Easyhaler ${ }^{\circledR}$ have a quite similar size and both inhalers have a dose counter, Easyhaler ${ }^{\mathbb{B}}$ also provides dosing feedback to the patient with the taste of lactose [40]. Describing the "ideal" inhalation device, consistency of the dose emitted is a crucial aspect. With regards to stability, a study [41] was organized to compare in vitro drug delivery characteristics of two BUD/FORM dry powder inhalers, the Easyhaler ${ }^{\circledR}$ and the Turbuhaler $^{\mathbb{B}}$, at different patient air flow rates, and to test dose delivery from the Easyhaler ${ }^{\circledR}$ in stressed conditions exposed to moisture, dropping, vibration and freezing/thawing. The Delivered Dose (DD) of budesonide and formoterol (Figure 2a,2b) at the three different flow rates was expressed as a percent of the labelled doses delivered from the BUD/FORM Easyhaler $^{\circledR}$ and Turbuhaler ${ }^{\circledR}$. The variability in dose delivery from the Easyhaler ${ }^{\circledR}$ was statistically significantly smaller than from the Turbuhaler ${ }^{\circledR}$

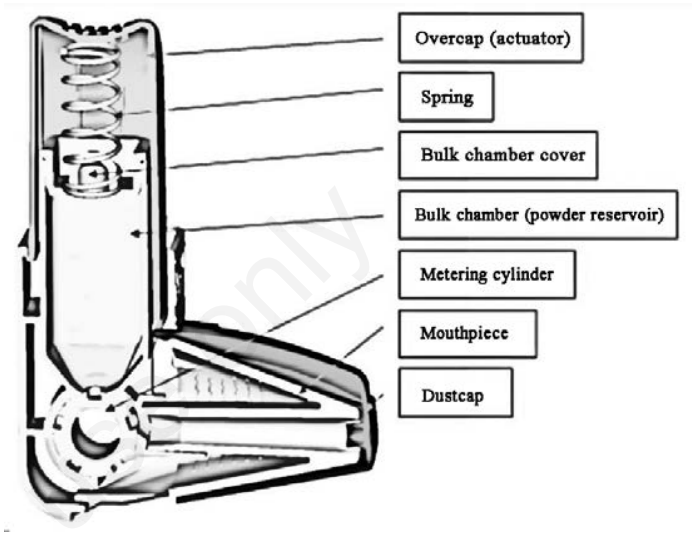

Figure 1. Cross section of the Easyhaler multi-dose powder inhaler. Reproduced from [30]; with permission.
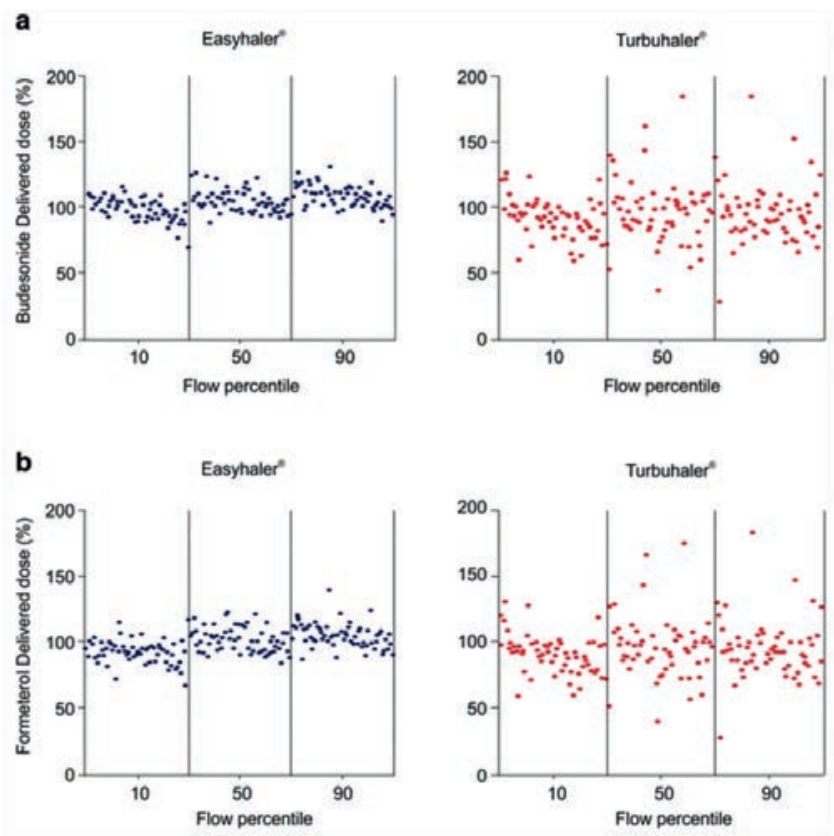

Figure 2. Dose delivery of budesonide (a) and formoterol (b) from two budesonide/formoterol multi-dose DPIs, the Easyhaler ${ }^{\circledR}$ and the Turbuhaler ${ }^{\circledR}(160 / 4.5 \mu \mathrm{g})$ at three different flow rates. The delivered dose is expressed as a percent of the nominal labelled dose. Each data print represents a single dose actuation. Reproduced from [41]. http://creativecommons.org/ licenses/by-nc/4.0/ 
for both budesonide and formoterol and this was true at all three flow rates.

Figure 3a shows the DD of the three BUD/FORM Easyhalers ${ }^{\circledR}$ taken in the beginning (doses 1-3), at the middle and at the end of the Easyhaler ${ }^{\circledR}$ lifespan when the first doses are set to $100 \%$, overall, DD varied from $94 \%$ to $103 \%$ for the three presentations at the middle and at the end of the Easyhaler ${ }^{\circledR}$ content. Figure $3 \mathrm{~b}$ shows the Fine Particle Dose (FPD), which represents respirable aerosol, at the beginning and at the end of the Easyhaler ${ }^{\circledR}$ (Figure $\left.3 a, b\right)$. It can be concluded that the influence of the number of actuations had only a slight effect on product properties and patients can inhale the correct dose throughout the inhaler life and receive the drug they need.

The effect of environmental moisture $\left(30^{\circ} \mathrm{C} / 75 \% \mathrm{RH}\right)$ on DD and FPD of the three strengths of the BUD/FORM in Easyhaler ${ }^{\circledR}$ is shown in Figure $4 \mathrm{a}, \mathrm{b}$.

In the same stability study [41] dropping the Easyhaler ${ }^{\mathbb{B}}$ from 1 meter did not result in changes in DD of budesonide or formoterol. Vibration, freezing and thawing did not affect neither delivered nor fine particle dose of the BUD/FORM Easyhaler ${ }^{\circledR}$. When the final version of the BUD/FORM Easyhaler ${ }^{\circledR}$ inhaler was compared with the commercially available BUD/FORM Turbuhaler ${ }^{\circledR}$ inhaler the conclusion was that there is no reason to believe that differences in clinical safety and efficacy would be demonstrable between the two tested inhalers. Thus, the excellent dosing accuracy of the Easyhaler $^{\circledR}$ documented with other substances has been maintained with BUD/FORM.

These studies showed that the Easyhaler ${ }^{\circledR}$ is tolerant to real-life environmental stress as DD and FPD are virtually unaffected by environmental factors.

Patients' preferences among 3 DPIs (Easyhaler ${ }^{\circledR}$, Turbuhaler ${ }^{\circledR}$ and Accuhaler ${ }^{\circledR}$ ) has been investigated: the Easyhaler ${ }^{\circledR}$ was the first choice for $53 \%$ of patients, the Turbuhaler ${ }^{\circledR}$ for $27 \%$, and the Accuhaler ${ }^{\circledR}$ for $20 \%$ [42]. The Easyhaler ${ }^{\circledR}$ has also demonstrated patient acceptability advantages, mainly because it is easy to use [33,40,43-47].

The advantage of manageability of a unique, portable device can be considered attractive especially for young people leading an intense relational and working life, ambitious not to be point out as an asthmatic patient.

It is important to demonstrate non-inferiority of asthma control when switching inhaler from Turbuhaler ${ }^{\circledR}$ to Easyhaler ${ }^{\circledR}$ in order to satisfy patients' preference. Asthma Control Test (ACT), MiniAsthma Quality of Life Questionnaire (Mini-AQLQ) and spirometry were performed before switching inhalers and after 12 weeks. Patients switching from Turbuhaler ${ }^{\circledR}$ to Easyhaler $^{\circledR}$ had equivalent or better results regarding patient's control of their asthma [48]. In a real-world setting, naïve patients and patients who switched from their current inhaler to the Easyhaler ${ }^{\circledR}$, achieved better disease control and quality of life after 3 months from switching; in addition, most patients considered the Easyhaler ${ }^{\circledR}$ to be portable and easy to learn to use and keep clean, during daily activities [34].
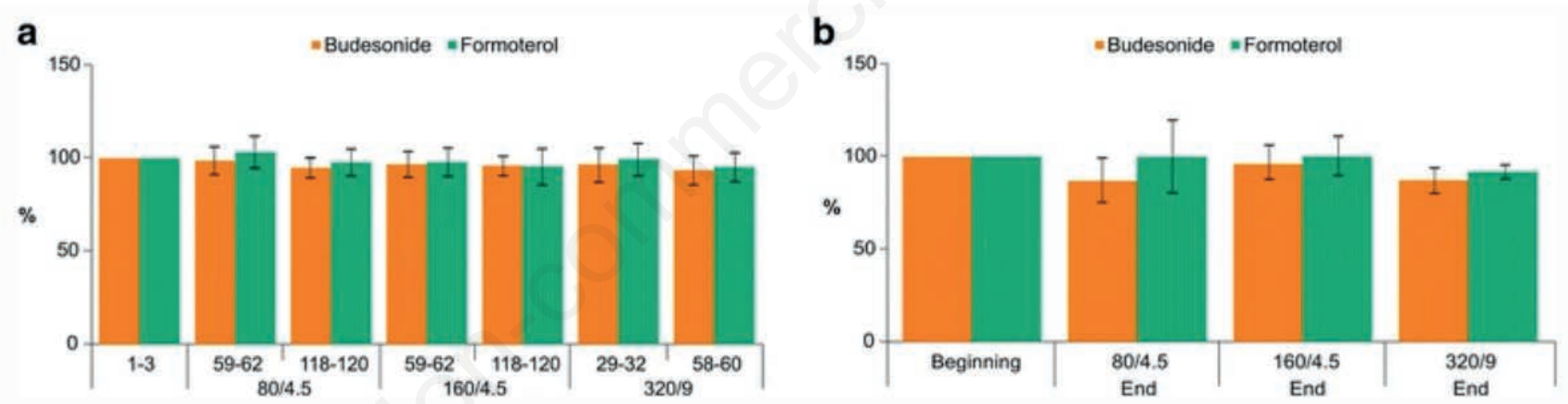

Figure 3. a) Delivered doses of $80 / 4.5,160 / 4.5$ and 320/9 $\mu \mathrm{g}$ in the budesonide/formoterol Easyhaler from the beginning (100\%), the middle, and the end of inhaler lifespan, expressed as deviations $\pm S D(n=6)$. b) Corresponding values for fine particle dose $(n=6)$. Reproduced from [41]. http://creativecommons.org/licenses/by-nc/4.0/
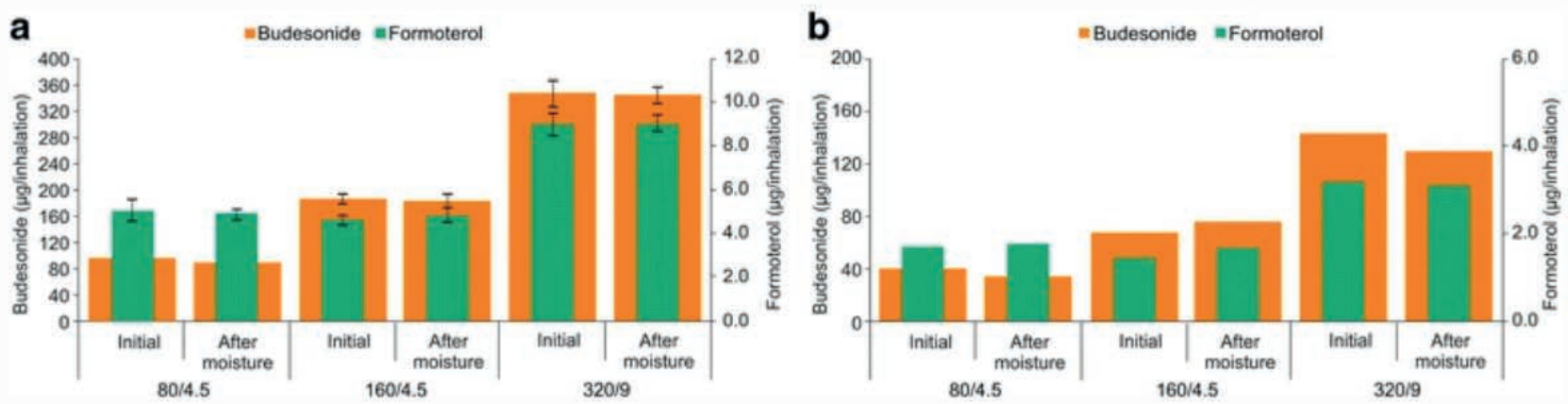

Figure 4. a) Effect of moisture on delivered dose of $80 / 4.5,160 / 4.5$ and $320 / 9 \mu \mathrm{g}$ in the budesonide/formoterol Easyhaler ( $\mathrm{n}=2$ ). $\mathrm{b}$ ) Corresponding values for fine particle dose. Reproduced from [41]. http://creativecommons. org/licenses/by-nc/4.0/ 
Results of randomized controlled trials may not predict effectiveness of inhaled drugs in the real life. In clinical practice the time to dedicate to patients training and education can be very important. In a real-world, multicenter, noninterventional study BUD/FORM Easyhaler ${ }^{\circledR}$ was evaluated for effectiveness, patient satisfaction, and physicians' assessments. Significant improvements in lung function, disease control, and health-related quality of life measures were reported after 12 weeks of BUD/FORM Easyhaler ${ }^{\circledR}$ use, $73.8 \%$ and $98.9 \%$ of patients learned the technique within 5 and $10 \mathrm{~min}$ of teaching, respectively. Therefore, it is likely that ease of use and adequate training on how to use the inhaler were important in ensuring the optimal dosing [49].

Considering all the characteristics examined, BUD/FORM Easyhaler $^{\circledR}$ is an inhaler device that comes very close to being an 'Idealhaler' in real-life conditions [42,46,50,51]: it could be considered effective, reproducible, precise, stable, and versatile. It is referred as easy to learn, to use and to keep clean but even comfortable, small, portable, and discreet.

\section{Conclusions}

Asthma control is enhanced by a strong adherence obtained through the combination in a single inhaler of both maintenance and reliever therapy and the availability of a device as close as possible to the characteristics of the ideal inhaler. Maintenance and Reliever Therapy has an established scientific rationale, as ICS and LABA have complementary actions on the pathophysiology of asthma.

Moreover, good results in terms of pharmacological asthma control may trigger a virtuous circle of adherence for patients who can rely on a device that guarantees accuracy, dose consistency and resistance to stress conditions, easy to learn, easy to be used, small, manageable, portable and discreet.

\section{References}

1. Croisant S. Epidemiology of asthma: Prevalence and burden of disease. Adv Exp Med Biol 2014;795:17-29.

2. Ghaffari J. The prevalence of children's asthma: A few comments. Clin Respir J 2018;12:2454.

3. Global Asthma Network [Internet]. Global Asthma Report 2014. Available from: http://www.globalasthmareport. org/2014/index.php

4. To T, Stanojevic S, Moores G, Gershon AS, Bateman ED, Cruz AA, et al. Global asthma prevalence in adults: findings from the cross-sectional world health survey. BMC Public Health 2012;12:204.

5. Bahadori K, Doyle-Waters MM, Marra C, Lynd L, Alasaly K, Swiston J, et al. Economic burden of asthma: a systematic review. BMC Pulm Med 2009;9:24.

6. Accordini S, Bugiani M, Arossa W, Gerzeli S, Marinoni A, Olivieri M, et al. Poor control increases the economic cost of asthma. A multicentre population-based study. Int Arch Allergy Immunol 2006;141:189-98.

7. Hoskins G, McCowan C, Neville RG, Thomas GE, Smith B, Silverman S. Risk factors and costs associated with an asthma attack. Thorax 2000;55:19-24.

8. WHO. Aderence to long-term therapies. Evidence for action. Available from: whqlibdoc.who.int/publications/2003/ 9241545992.pdf.

9. Partridge MR, van der Molen T, Myrseth S-E, Busse WW. Attitudes and actions of asthma patients on regular mainte- nance therapy: the INSPIRE study. BMC Pulm Med 2006;6:13.

10. Boulet LP, Vervloet D, Magar Y, Foster JM. Adherence. Clin Chest Med 2012;33:405-17.

11. Beasley R, Braithwaite I, Fingleton J, Weatherall M. The inhaled corticosteroid/long-acting $\beta$-agonist maintenance and reliever therapy regimen: where to from here? Eur Respir J 2018;51:1702338.

12. O'Byrne PM, Jenkins C, Bateman ED. The paradoxes of asthma management: time for a new approach? Eur Respir J 2017;50:1701103.

13. Global Initiative for Asthma - GINA [Internet]. 2020 Global Strategy for Asthma Management and Prevention. Available from: https://ginasthma.org/gina-reports/\#: : text $=2020 \% 20$ GINA\%20Report $\% 2$ C\%20Global\%20Strategy,on $\% 20$ the $\% 20$ GINA\%20Science\%20Committee

14. O'Byrne PM, FitzGerald JM, Bateman ED, Barnes PJ, Zhong $\mathrm{N}$, Keen $\mathrm{C}$, et al. Inhaled combined budesonide-formoterol as needed in mild asthma. N Engl J Med. 2018;378:1865-76.

15. Bateman ED, Reddel HK, O’Byrne PM, Barnes PJ, Zhong N, Keen C, et al. As-needed budesonide-formoterol versus maintenance budesonide in mild asthma. $\mathrm{N}$ Engl $\mathrm{J}$ Med. 2018;378:1877-87.

16. Beasley R, Holliday M, Reddel HK, Braithwaite I, Ebmeier S, Hancox RJ, et al. Controlled trial of budesonide-formoterol as needed for mild asthma. N Engl J Med 2019;380:2020-30.

17. Hardy J, Baggott C, Fingleton J, Reddel HK, Hancox RJ, Harwood M, et al. Budesonide-formoterol reliever therapy versus maintenance budesonide plus terbutaline reliever therapy in adults with mild to moderate asthma (PRACTICAL): a 52week, open-label, multicentre, superiority, randomised controlled trial. Lancet 2019;394:919-28.

18. Valero A, Olaguibel J, Delgado J, Plaza V, Álvarez F, Molina $\mathrm{J}$, et al. Re-evolution of asthma management: dilemmas and new paradigms. J Investig Allergol Clin Immunol 2019;29:1523.

19. Plaza Moral V, Alonso Mostaza S, Alvarez Rodríguez C, Gomez-Outes A, Gómez Ruiz F, López Vina A, et al. Spanish guideline on the management of asthma. J Investig Allergol Clin Immunol 2016;26:S1-92.

20. Reddel HK, Busse WW, Pedersen S, Tan WC, Chen YZ, Jorup $\mathrm{C}$, et al. Should recommendations about starting inhaled corticosteroid treatment for mild asthma be based on symptom frequency: a post-hoc efficacy analysis of the START study. Lancet 2017;389:157-66. d

21. Haahtela T, Herse F, Karjalainen J, Klaukka T, Linna M, Leskelä RL, et al. The Finnish experience to save asthma costs by improving care in 1987-2013. J Allergy Clin Immunol 2017;139:408-14.e2.

22. O’Byrne PM, Bisgaard H, Godard PP, Pistolesi M, Palmqvist $\mathrm{M}$, Zhu Y, et al. Budesonide/formoterol combination therapy as both maintenance and reliever medication in asthma. Am J Respir Crit Care Med 2005;171:129-36.

23. Jenkins CR, Bateman ED, Sears MR, O'Byrne PM. What have we learnt about asthma control from trials of budesonide/formoterol as maintenance and reliever? Respirology 2020. doi:10.1111/resp.13804.

24. Sobieraj DM, Weeda ER, Nguyen E, Coleman CI, White CM, Lazarus SC, et al. Association of Inhaled corticosteroids and long-acting $\beta$-agonists as controller and quick relief therapy with exacerbations and symptom control in persistent asthma. JAMA 2018;319:1485.

25. Laube BL, Janssens HM, de Jongh FHC, Devadason SG, Dhand R, Diot P, et al. What the pulmonary specialist should know about the new inhalation therapies. Eur Respir $\mathrm{J}$ 
2011;37:1308-417.

26. Dal Negro RW. Dry powder inhalers and the right things to remember: a concept review. Multidiscip Respir Med 2015;10:13. doi:10.1186/s40248-015-0012-5.

27. Lavorini F, Magnan A, Christophe Dubus J, Voshaar T, Corbetta L, Broeders M, et al. Effect of incorrect use of dry powder inhalers on management of patients with asthma and COPD. Respir Med 2008;102:593-604.

28. Virchow JC, Akdis CA, Darba J, Dekhuijzen R, Hartl S, Kobelt $\mathrm{G}$, et al. A review of the value of innovation in inhalers for COPD and asthma. J Mark Access Health Policy 2015;3: 28760.

29. Vidgren M, Silvasti M, Vidgren P, Sormunen H, Laurikainen K, Korhonen P. Easyhaler ${ }^{\circledR}$ multiple dose powder inhaler Practical and effective alternative to the pressurized MDI. Aerosol Sci Technol 1995;22:335-45.

30. Lavorini F. Easyhaler ${ }^{\circledR}$ : An overview of an inhaler device for day-to-day use in patients with asthma and chronic obstructive pulmonary disease. Drugs Context 2019;8:212596.

31. Clark Ar, Hollingworth Am. The relationship between powder inhaler resistance and peak inspiratory conditions in healthy volunteers - Implications for in vitro testing. J Aerosol Med 1993;6:99-110.

32. Valero A, Ribó P, Maíz L, Barbero E, Calle M, Campo C, et al. Asthma patient satisfaction with different dry powder inhalers. Expert Rev Respir Med 2019;13:133-8.

33. De Blaquiere P, Christensen DB, Carter WB, Martin TR. Use and misuse of metered-dose inhalers by patients with chronic lung disease. A controlled, randomized trial of two instruction methods. Am Rev Respir Dis 1989;140:910-6.

34. Tamási L, Szilasi M, Gálffy G. Clinical effectiveness of budesonide/formoterol fumarate Easyhaler ${ }^{\circledR}$ for patients with poorly controlled obstructive airway disease: a real-world study of patient-reported outcomes. Adv Ther 2018;35:1140-52.

35. Schweisfurth H, Malinen A, Koskela T, Toivanen P, RankiPesonen M, German Study Group. Comparison of two budesonide powder inhalers, Easyhaler and Turbuhaler, in steroidnaïve asthmatic patients. Respir Med 2002;96:599-606.

36. Lahelma S, Kirjavainen M, Kela M, Herttuainen J, Vahteristo M, Silvasti M, et al. Equivalent lung deposition of budesonide in vivo: a comparison of dry powder inhalers using a pharmacokinetic method. Br J Clin Pharmacol 2005;59:167-73.

37. Hämäläinen KM, Granander $\mathrm{M}$, Toivanen $\mathrm{P}$, Malinen A. Assessment of the systemic effects of budesonide inhaled from Easyhaler and from Turbuhaler in healthy male volunteers. Respir Med. 2001;95:863-9.

38. Tukiainen H, Rytilä P, Hämäläinen KM, Silvasti MSL, KeskiKarhu J, Finnish Study Group. Safety, tolerability and acceptability of two dry powder inhalers in the administration of budesonide in steroid-treated asthmatic patients. Respir Med. 2002;96:221-9.
39. Vanto T, Hämäläinen KM, Vahteristo $M$, Wille $S$, Njå F, Hyldebrandt N, et al. Comparison of two budesonide dry powder inhalers in the treatment of asthma in children. J Aerosol Med. 2004;17:15-24.

40. Lähelmä S, Vahteristo M, Metev H, Taseva M, Stamatova N, Bartha A, et al. Equivalent bronchodilation with budesonide/formoterol combination via Easyhaler and Turbuhaler in patients with asthma. Respir Med 2016;120:315.

41. Haikarainen J, Selroos O, Löytänä T, Metsärinne S, Happonen A, Rytilä P. Budesonide/formoterol Easyhaler ${ }^{\circledR}$ : Performance under simulated real-life conditions. Pulm Ther 2017;3:12538.

42. Giner J, Torrejón M, Ramos A, Casan P, Granel C, Plaza V, et al. [Patient preference in the choice of dry powder inhalers].[Article in Spanish]. Arch Bronconeumol 2004;40:106-9.

43. Nsour WM, Alldred A, Corrado J, Chrystyn H. Measurement of peak inhalation rates with an in-check meter to identify an elderly patient's ability to use a turbuhaler. Respir Med 2001;95:965-8.

44. Lenney J, Innes JA, Crompton GK. Inappropriate inhaler use: assessment of use and patient preference of seven inhalation devices. EDICI. Respir Med 2000;94:496-500.

45. Jäger L, Laurikainen $K$, Leinonen $M$, Silvasti $M$. Beclomethasone dipropionate Easyhaler is as effective as budesonide Turbohaler in the control of asthma and is preferred by patients. German Study Group. Int J Clin Pract $54: 368-72$

46. Rönmark E, Jögi R, Lindqvist A, Haugen T, Meren M, Loit H, et al. Correct use of three powder inhalers: comparison between Diskus, Turbuhaler, and Easyhaler. J Asthma 2005;42:173-8.

47. Syk J, Vinge I, Sörberg M, Vahteristo M, Rytilä P. A multicenter, observational, prospective study of the effectiveness of switching from budesonide/formoterol Turbuhaler ${ }^{\circledR}$ to budesonide/formoterol Easyhaler®. Adv Ther 2019;36:1756-69.

48. Rytilä P, Syk J, Vinge I SM. Switch from Symbicort Turbuhaler to Bufomix Easyhaler; a real-life prospective study in asthma patients. Eur Resp J 2018;52:PA3998.

49. Selroos O, Löfroos AB, Pietinalho A, Riska H. Comparison of terbutaline and placebo from a pressurised metered dose inhaler and a dry powder inhaler in a subgroup of patients with asthma. Thorax 1994;49:1228-30.

50. Chrystyn H. Closer to an "ideal inhaler" with the Easyhaler ${ }^{\circledR}$ : An innovative dry powder inhaler. Clin Drug Investig 2006;26:175-83.

51. Chrystyn H, Haahtela T. Real-life inhalation therapy - Inhaler performance and patient education matter. Eur Respir Dis 2012;8:11-8.

Received for publication: 9 February 2020. Accepted for publication: 9 July 2020.

This work is licensed under a Creative Commons Attribution-NonCommercial 4.0 International License (CC BY-NC 4.0).

(C) Copyright: the Author(s), 2020

Licensee PAGEPress, Italy

Multidisciplinary Respiratory Medicine 2020; 15:649

doi:10.4081/mrm.2020.649 